\title{
Karun Devkota $^{1}$, Kapil Adhikari ${ }^{1}$, Sapana Koirala ${ }^{1}$, Ashok Chapagain ${ }^{1}$
}

${ }^{1}$ Department of Radiodiagnosis and Imaging, BPKIHS, Dharan, Nepal.

\section{Correspondence}

Dr. Karun Devkota

Department of Radiodiagnosis and Imaging, BPKIHS, Dharan, Nepal.

Email:karundevkota@gmail.com

Article received: Jan 302020

Article accepted: June 72020

\section{ABSTRACT}

Sturge-Weber syndrome (SWS) is a rare congenital vascular disorder characterized by facial capillary malformation, associated capillary-venous malformations affecting the brain and eye along with calcification in the occipital or frontoparietal region. Occipital and posterior parietal lobes are the common site of involvement in SWS. Posterior fossa involvement is a rare finding with very few number of reported cases. Contrast enhanced MRI is considered as the gold standard for the diagnosis of SWS demonstrating the enhancement of pial angioma.

Keywords: Sturge Weber Syndrome, posterior fossa

fossa involvement is a rare finding in SWS, and reported cases are exceedingly scarce in literature. ${ }^{4}$

\section{CASE REPORT}

We report here a case of a six year female who presented to our institute B.P. Koirala Institute of Health Sciences (BPKIHS), Dharan with complain of recurrent seizure. Clinical examination revealed facial port wine stain on right side involving the right forehead, orbital region and cheek (Fig 1.a). Hemiplegia of the left upper and lower limb was also present. Non Contrast Computed Tomography (NCCT) scan showed extensive calcification in right fronto-temporo-parietal lobes with hemiatrophy of right side (Fig. 1.b). Magnetic Resonance Imaging (MRI) showed extensive leptomeningeal enhancement in the fronto-temporo-parietal lobes along with right cerebellar hemisphere (Fig. 1.c). Mild brain atrophy of the right side was noted.

Occipital and posterior parietal lobes are the common site of involvement in SWS. Posterior 


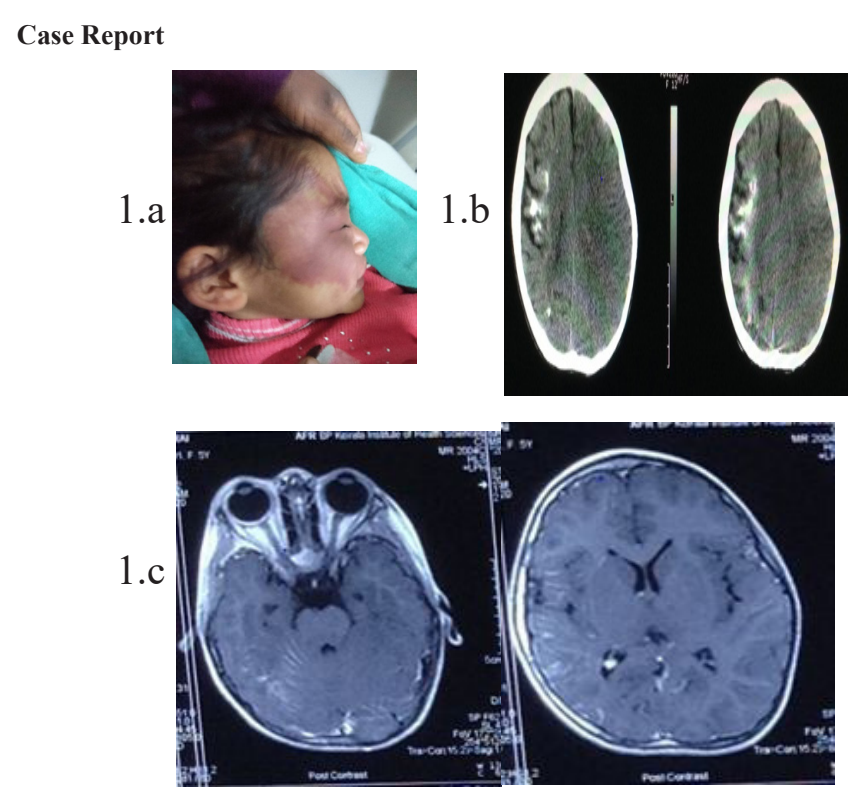

\section{DISCUSSION}

Schimer is usually credited with the first description of SWS in 1860. In 1879, Sturge gave a clinical description of one patient with facial naevus flammeus and contralateral neurological symptoms. $\mathrm{He}$ raised the possibility of an intracranial angiomatous malformation accompanying the facial naevus. Weber is credited with the first radiological report of intracranial calcification on a plain skull radiograph. ${ }^{4}$

Contrast enhanced MRI is considered as the gold standard for the diagnosis of SWS as it has higher sensitivity in demonstrating the enhancement of pial angioma and may provide diagnosis despite normal or nonspecific CT, non contrast MRI or angiography. ${ }^{5}$ The patient described in our report demonstrated many of the characteristic clinical and imaging findings of Sturge-Weber syndrome. In addition, there was an unusual finding of cerebellar involvement as demonstrated by MRI.

Angiography characteristically shows delayed opacification or nonopacification of the dysplastic or thrombosed superficial cortical veins with shunting and opacification of dilated medullary and deep veins. ${ }^{6}$

The fundamental abnormality in SWS is lack of superficial cortical venous drainage of the affected hemisphere. The cause of this abnormality may be
Medical Journal of Pokhara Academy of Health Sciences Vol. 3 Issue 2 due to failure of development of superficial cortical veins or the result of venous thrombosis during the early embryological period. The lack of superficial venous drainage has two effects. First, blood is redirected into the developing leptomeninges causing the development of abnormal vascular channels i.e. leptomeningeal angiomatosis, which is the hallmark of SWS. Secondly blood flow gets redirected into the deep venous system causing persistence of embryological venous structures which increases the risk of variety of developmental arteriovenous anomalies. As the diverted cortical venous blood into the deep system and leptomeninges can't compensate fully for the lack of superficial veins , resulting long term vascular stasis and hypoxia lead to tissue damage and dystrophic calcification. ${ }^{4}$

T. Decker et al postulated that facial nevi in the trigeminal distribution may be associated with cerebellar leptomeningeal vascular anomalies occasionally because of the persistence of primordial sinusoidal vascular channels between the portion of the ectoderm forming the face and the portion of the underlying ventral neural tube that forms the rhombencephalon. ${ }^{6}$

MS Pearl et al. explained involvement of both supra and infratentorial compartments can be attributed by the defective development of embryonic cortical veins simultaneously involving the telencephalic and rhombencephalic vesicles. They also reported that simultaneous supra and infratentorial involvement may represent a more severe end of the spectrum of SWS. ${ }^{7}$

\section{REFERENCES}

1. Zanzmera P, Patel T, Shah V. Diagnostic dilemma: Sturge-Weber syndrome, without facial nevus. Journal of neurosciences in rural practice. 2015 Jan;6(1):105.

2. Ramli N, Sachet M, Bao C, Lasjaunias P. Cerebrofacial venous metameric syndrome (CVMS) 3: Sturge-Weber syndrome with bilateral lymphatic/venous malformations of the mandible. Neuroradiology. 2003 Oct 
$1 ; 45(10): 687-90$.

3. Comi AM. Presentation, diagnosis, pathophysiology and treatment of the neurologic features of Sturge-Weber Syndrome. The neurologist. 2011 Jul;17(4):179.

4. Griffiths PD. Sturge-Weber syndrome revisited: the role of neuroradiology. Neuropediatrics. 1996 Dec;27(06):284-94.

5. Benedikt RA, Brown DC, Walker R, Ghaed VN, Mitchell M, Geyer CA. Sturge-Weber syndrome: cranial MR imaging with GdDTPA. American journal of neuroradiology. 1993 Mar 1;14(2):409-15.

6. Decker T, Jones K, Barnes P. Sturge-Weber syndrome with posterior fossa involvement. American journal of neuroradiology. 1994 Feb 1;15(2):389-92.

7. Pearl MS, Abdalla WM, Lin DD, Comi AM, Boltshauser E, Gailloud P, Huisman TA. Sturge-Weber syndrome with cerebellar involvement. Journal of neuroradiology. 2009 Mar 31;36(1):57-60. 